\title{
Acute Abdomen as a Presentation of Covid 19 in Children: Our Early Experience
}

ISSN: 2576-9200

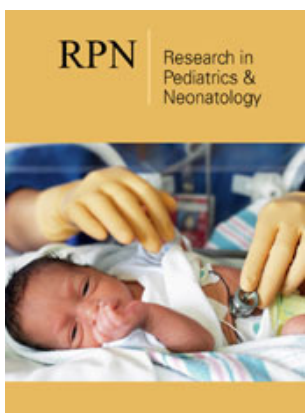

*Corresponding author: Samiul Hasan, Assistant Professor, Division of Pediatric Surgery, Dhaka Shishu (Children) Hospital, Dhaka, Bangladesh

Submission: 侮 July 20, 2020

Published: 㭗July 31, 2020

Volume 4 - Issue 5

How to cite this article: Samiul Hasan Ayub Ali and Umama Huq. Acute Abdomen as a Presentation of Covid 19 in Children: Our Early Experience. 4(5). RPN. 000596. 2020.

DOI: $10.31031 /$ RPN.2020.04.000596

Copyright $@$ Samiul Hasan. This article is distributed under the terms of the Creative Commons Attribution 4.0 International License, which permits unrestricted use and redistribution provided that the original author and source are credited.

\section{Samiul Hasan ${ }^{1 *}$, Ayub Ali ${ }^{2}$ and Umama Huq ${ }^{3}$}

${ }^{1}$ Assistant Professor, Division of Pediatric Surgery, Dhaka Shishu (Children) Hospital, Bangladesh

${ }^{2}$ Assistant Professor \& Resident surgeon, Division of Pediatric Surgery, Dhaka Shishu (Children) Hospital, Bangladesh

${ }^{3}$ Resident, Division of Pediatric Surgery, Dhaka Shishu (Children) Hospital, Bangladesh

\begin{abstract}
Background: COVID-19 is currently a public health emergency around the world. Increasingly more people are being identified with this deadly viral disease. Though children experience a milder disease course, severe and life threatening disease has also been reported. An atypical presentation may delay the diagnosis, isolation, and treatment. The aim of this study was to share our experience of atypical presentation of COVID-19 cases as acute abdomen in children.
\end{abstract}

Method: We retrospectively reviewed data of all children diagnosed to have COVID 19 in our department between April to June 2020. Epidemiological \& clinical data of children presented with acute abdomen were retrieved and placed in Microsoft Excel 2016. The data were then analyzed and literature reviewed.

Result: Total 32 children were diagnosed to have COVID 19 during this period. Six children among them presented with features of acute abdomen, without any respiratory symptom. The diagnostic workout for acute abdomen did not match clinical diagnosis rather RT PCR of nasopharyngeal swab was positive for SARS CoV 2. Four of them were female and 2 were male. Age range was 3 years 10 months to 14 years. Only one patient had radiological evidence of lung injury. All of them improved clinically within 4 days and were discharged from the hospital with advice for home isolation.

Conclusion: The clinical course of COVID 19 is yet to understand completely. A high index of suspicion is required for early diagnosis of children with atypical presentation to reduce further transmission of the disease and to avoid serious complications. .

Keywords: COVID-19; Acute abdomen; COVID-19 in Children; Atypical presentation of COVID-19; Diagnosis of COVID-19

\section{Introduction}

More than 10 million people around the world have been infected with SARS CoV 2 [1]. Bangladesh detected its first case of COVID-19 on $8^{\text {th }}$ March, 2020. Following this, 141,801 confirmed cases were recorded till $29^{\text {th }}$ June with a case fatality rate of $1.26 \%$ [2]. Fortunately, the infection rate in much less in children compared to adults. Data from China and the US showed that around $2 \%$ of confirmed cases are below 20 years of age $[3,4]$. In Bangladesh it is around $8 \%$ [2]. Therefore, clear information about clinical features and course of the disease in children is scarce till now. Children infected with SARS CoV 2 are mostly asymptomatic or show mild symptoms but critical illness and even death has been reported in children especially those with pre-existing medical conditions. The presenting symptoms are also variable in children. The typical respiratory problems and fever are infrequent in children [4-10]. Severe gastrointestinal symptoms have also been reported as the presenting features of COVID-19 in children [11]. These can lead to confusion about the diagnosis and may cause delays in isolation and treatment and these patients can transmit the disease further while not being identified early. Delayed diagnosis may also lead to serious complications. The aim of this study was to share our experience of atypical presentation of COVID-19 cases as acute abdomen in children.

\section{Methods}

This is a retrospective study. We collected data of all children diagnosed to have COVID 19 in our department between April to June 2020 from our hospital record. Diagnosis 
of COVID 19 was confirmed in all patients using RT PCR test of nasopharyngeal swab for SARS CoV 2. Epidemiological \& clinical data of children presented with acute abdomen were retrieved and placed in Microsoft Excel 2016. The data were then analyzed and literature reviewed. Ethical permission has been taken from hospital ethical review board.

\section{Results}

Total 32 children were diagnosed to have COVID 19 during this study period. Among them 6 patients presented with features of acute abdomen such as sudden, severe abdominal pain and several episodes of non-bilious vomiting. Detailed epidemiological and clinical data are shown in Table 1 . Age of the patients ranges from 3 years 10 months to 14 years. Four patients were female, and two were male. There was no respiratory symptom in any of the patients. After the initial evaluation, the provisional diagnosis was acute appendicitis in four patients and acute pancreatitis in two patients, but laboratory and imaging findings did not match the provisional diagnoses. Initially, we treated the patients with analgesic and empirical antibiotics. Real-time polymerase chain reaction (RT PCR) of the nasopharyngeal swab was found positive for novel coronavirus in all six patients and only one patient had left lower zone opacity in chest x-ray (Figure 1). All of them improved clinically within 4 days without any respiratory support and were discharged from the hospital with advice for home isolation.

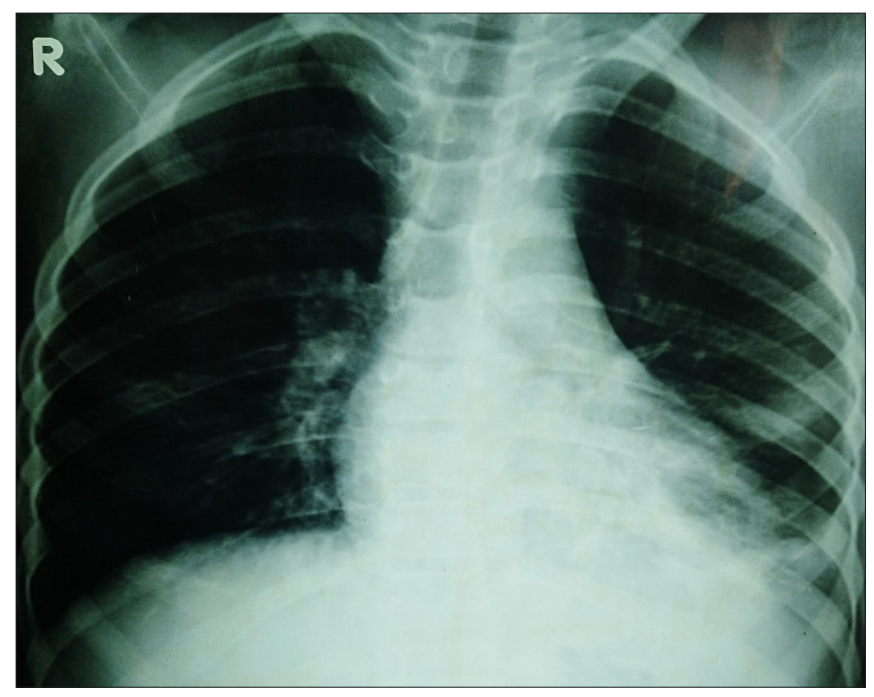

Figure 1: X ray showing opacity in left lower lung zone.

Table 1: Demographic \& clinical data of all six patients.

\begin{tabular}{|c|c|c|c|c|c|c|}
\hline Variables & Case 1 & Case2 & Case 3 & Case 4 & Case 5 & Case 6 \\
\hline Age & $5 y 6 \mathrm{~m}$ & $9 y 6 m$ & $14 y$ & $3 y 10 \mathrm{~m}$ & $10 y$ & $10 y$ \\
\hline Gender & Female & Female & Male & Male & Female & Female \\
\hline Exposure history & Unknown & Unknown & Unknown & Unknown & Unknown & Unknown \\
\hline \multicolumn{7}{|l|}{ Presenting features } \\
\hline Abdominal pain & Yes & Yes & Yes & Yes & Yes & Yes \\
\hline Vomiting & Yes & Yes & Yes & Yes & Yes & No \\
\hline Diarrhea & No & No & No & No & No & No \\
\hline Fever & $2^{\text {nd }}$ day & Yes & No & No & Yes & Yes \\
\hline Cough & No & No & No & No & No & No \\
\hline Sneezing & No & No & No & No & No & No \\
\hline Sore throat & No & No & No & No & No & No \\
\hline Rhinorrhea & No & No & No & No & No & No \\
\hline Dyspnea & No & No & No & No & No & No \\
\hline \multicolumn{7}{|l|}{ Clinical examination } \\
\hline Abdominal distention & No & No & No & No & No & No \\
\hline
\end{tabular}




\begin{tabular}{|c|c|c|c|c|c|c|}
\hline Abdominal tenderness & $\begin{array}{l}\text { Around umbi- } \\
\quad \text { licus }\end{array}$ & Right iliac fossa & Epigastrium & $\begin{array}{l}\text { Mild, General- } \\
\text { ized }\end{array}$ & Central & Right lumber \\
\hline Provisional diagnosis & $\begin{array}{l}\text { Acute appendi- } \\
\text { citis }\end{array}$ & $\begin{array}{l}\text { Acute appendi- } \\
\text { citis }\end{array}$ & $\begin{array}{l}\text { Acute pancre- } \\
\text { atitis }\end{array}$ & $\begin{array}{l}\text { Acute appendi- } \\
\text { citis }\end{array}$ & $\begin{array}{l}\text { Acute pancre- } \\
\text { atitis }\end{array}$ & Acute appendicitis \\
\hline Abdominal sonography & Normal & $\begin{array}{l}\text { Mild collection } \\
\text { in pelvis }\end{array}$ & Normal & $\begin{array}{l}\text { Distended bowel } \\
\text { loops }\end{array}$ & $\begin{array}{l}\text { Swollen pan- } \\
\text { crease }\end{array}$ & Pelvic collection \\
\hline RT PCR & Positive & Positive & Positive & Positive & Positive & Positive \\
\hline Chest $X$ ray & Normal & Normal & Normal & Normal & Normal & $\begin{array}{l}\text { Opacity in left } \\
\text { lower zone }\end{array}$ \\
\hline WBC count & Normal & Normal & Raised & Raised & Raised & Normal \\
\hline Neutrophil & Raised & Normal & Raised & Normal & Raised & Raised \\
\hline Lymphocyte & Normal & Raised & Normal & Raised & Normal & Normal \\
\hline Hemoglobin & Normal & Normal & Normal & Normal & Normal & Normal \\
\hline Platelet & Normal & Normal & Normal & Normal & Normal & Normal \\
\hline Serum amylase, lipase & Not done & Not done & Normal & Not done & Normal & Not done \\
\hline CRP & Normal & Normal & Normal & Raised & Raised & Raised \\
\hline \multicolumn{7}{|l|}{ Treatment } \\
\hline Symptomatic & Yes & Yes & Yes & Yes & Yes & Yes \\
\hline Antibiotic & Yes & Yes & Yes & Yes & Yes & Yes \\
\hline Outcome & Improved & Improved & Improved & Improved & Improved & Improved \\
\hline Discharge & $4^{\text {th }}$ day & $5^{\text {th }}$ day & $4^{\text {th }}$ day & $4^{\text {th }}$ day & $5^{\text {th }}$ day & $5^{\text {th }}$ day \\
\hline
\end{tabular}

\section{Discussion}

Our hospital is the largest dedicated pediatric hospital in the country, but it was not assigned for COVID-19 treatment till June 2020. From the middle of March, we cancelled all elective admission to limit the spread of COVID-19 and admitted only emergency patients without COVID-19 symptoms. A nasopharyngeal swab is taken from all patients for RT PCR to exclude asymptomatic COVID-19 cases. A chest X-ray is used for the immediate isolation of suspected cases. None of the six patients had any respiratory symptoms. Reports from China and the US justify this presentation. A significant proportion of children with COVID-19 do not have a respiratory problem, and those who are symptomatic, experience a milder course of the disease $[4,5,7]$. This is thought to be due to lower inflammatory response to lung injuries in children. Younger children experience mild symptoms but lung injury can occur even in asymptomatic patients [7]. One of our patients ( $\left.6^{\text {th }}\right)$ had radiological evidence of lung injury. Cai J et al. [5]. reported only four out of ten children had lung opacity in chest X-ray [5]. Cai X et al. [11] reported radiological evidence of lung injury without respiratory symptoms [11].

Abdominal pain \& vomiting as symptoms of COVID-19 is not frequent. In 2 series from China reported by Cai J et al. \& Du W et al. $[5,7]$ showed no children with abdominal pain \& vomiting $[5,7]$ but a report from the USA showed $5.8 \%$ of pediatric patients were having abdominal pain [4]. Cai X et al. [11] reported 5 children with nonrespiratory presentation of COVID-19, all of them presented with gastrointestinal symptoms. It is still not clear why gastrointestinal symptoms are more common in children. It is hypothesized that as ACE2 receptor is abundant in the intestinal epithelium and children cannot maintain adequate hand hygiene, therefore more susceptible to infection through digestive tract [11]. Cai J et al. [5] detected an abnormally high frequency of virus shedding in feces of COVID-19 infected children which indicates viral replication in intestine [5]. The acute abdomen has also been reported as a manifestation of influenza virus infection in adolescents. The exact pathology of this manifestation is not clear [12]. Any viral infection of the gastrointestinal tract can cause mesenteric lymphadenitis and may lead to an acute abdomen [13]. Even segmental and lobar pneumonias in children may cause mesenteric lymphadenitis and abdominal pain [14]. No case received antiviral drugs. According to their provisional diagnoses, an empirical antibiotic was started initially for all patients, which was not for COVID-19. All patients improved clinically within 4 to 5 days of hospital admission, probably due to the milder course of the disease.

\section{Conclusion}

COVID 19 is still a puzzle to the clinicians, which is yet to be solved. A high index of suspicion is required to diagnose children with atypical presentations. Children with acute abdomen should be isolated and investigated for COVID-19 during an epidemic. Though most children experience a milder disease in COVID-19, early diagnosis would reduce transmission, patient sufferings, and avoid unnecessary antibiotic use.

\section{References}

1. (2020) WHO Coronavirus disease (COVID-19) Dashboard. Switzerland

2. (2020)WHO Bangladesh COVID-19 morbidity and mortality weekly update (MMWU). WHO Bangladesh 18: 1-17. 
3. Wu Z, McGoogan JM (2020) Characteristics of and important lessons from the coronavirus disease 2019 (COVID-19) outbreak in China: Summary of a report of 72314 cases from the Chinese center for disease control and prevention. JAMA 323(13): 1239-1242.

4. CDC Covid-19 Team (2020) Coronavirus disease 2019 in childrenUnited States, February 12-April 2, 2020. MMWR Morb Mortal Wkly Rep 69(14): 422-426.

5. Cai J, Xu J, Lin D, Yang Z, Xu L, et al. (2020) A case series of children with 2019 novel coronavirus infection: Clinical and epidemiological features. Clin Infect Dis 1-6.

6. Lu X, Zhang L, Du H, Zhang J, Li YY, et al. (2020) SARS-CoV-2 Infection in children. N Engl J Med 382(17): 1663-1665.

7. Du W, Yu J, Wang H, et al. (2020) Clinical characteristics of COVID-19 in children compared with adults in Shandong province, China. Infection 48(3): 445-452.

8. Wang Z, Zhou Q, Wang C, Shi Q, Lu S, et al. (2020) Clinical characteristics of children with COVID-19: A rapid review and meta-analysis. Ann Transl Med 8(10): 620.
9. Shekerdemian LS, Mahmood NR, Wolfe KK, Riggs BJ, Ross CE, et al. (2020) Characteristics and outcomes of children with coronavirus disease 2019 (covid-19) infection admitted to us and Canadian pediatric intensive care units. JAMA Pediatr.

10. Qiu L, Jiao R, Zhang A, Chen X, Ning Q et al. (2020) A typical case of critically Ill infant of coronavirus disease 2019 with persistent reduction of t lymphocytes. Pediatr Infect Dis J 39(7): e87-e90.

11. Cai X, Ma Y, Li S, Chen Y, Rong Z, et al. (2020) Clinical characteristics of 5 COVID-19 cases with non-respiratory symptoms as the first manifestation in children. Front Pediatr 8: 1-9.

12. Vivar KL, Uyeki TM (2014) Influenza virus infection mimicking an acute abdomen in a female adolescent. Influenza Other Respir Viruses 8(2): 140-141.

13. Helbling R, Conficconi E, Wyttenbach M, Benetti C, Simonetti GD, et al. (2017) Acute nonspecific mesenteric lymphadenitis: More than "No need for surgery". Biomed Res Int 2017: 1-4.

14. Moustaki M, Zeis PM, Katsikari M, Fretzayas A, Grafakou O, et al. (2003) Mesenteric lymphadenopathy as a cause of abdominal pain in children with lobar or segmental pneumonia. Pediatr Pulmonol 35(4): 269-273.

For possible submissions Click below: 